Running head: CAMPAIGN MESSAGES AND MINORITY STRESS

Please cite as: Frost, D. M., \& Fingerhut, A. W. (in press). Daily exposure to negative campaign messages decreases same-sex couples' psychological and relational well-being.

Group Processes \& Intergroup Relations.

Daily Exposure to Negative Campaign Messages Decreases Same-Sex Couples' Psychological and Relational Well-Being

\author{
David M. Frost* \\ University of Surrey \\ Adam W. Fingerhut \\ Loyola Marymount University
}

* Corresponding Author

David M. Frost, Ph.D.

University of Surrey

School of Psychology

Department of Psychological Sciences

Guildford, Surrey GU1 4BP

United Kingdom

d.frost@surrey.ac.uk 


\begin{abstract}
Throughout history, the rights of stigmatized minority group members have been subject to popular debate and voter referenda. The impact of the resulting devaluing social discourse on the well-being of minority group members remains unknown. Most recently, exposure to the discourse leading up to decisions on same-sex marriage may have negative consequences for sexual minority individuals and same-sex couples. We examined the impact of exposure to same-sex marriage campaign messages (e.g., commercials, billboards, yard signs) on the psychological and relational well-being of couples living in the four states that had same-sex marriage voter initiatives in the 2012 general election. Sixty-two same-sex couples $(N=124)$ completed a baseline survey and 10 daily diary reports during the month before the election. Daily exposure to negative campaign messages was associated with increased negative affect and decreased positive affect and relationship satisfaction. These associations persisted controlling for baseline levels of depression and daily fluctuations in general stress among both members of the couple. Exposure to a devaluing social discourse regarding the rights of same-sex couples represents a unique form of social stress resulting in negative consequences for the psychological and relational well-being of same-sex couples. Thus, the health of same-sex couples may be of particular concern in contexts where marriage policy decisions are pending and the subject of popular debate.
\end{abstract}




\section{Daily Exposure to Negative Campaign Messages Decreases Same-Sex Couples' Psychological and Relational Well-Being}

Throughout history, the rights of minority groups with disadvantaged social status have been subject to popular vote and judicial decision-making by members of dominant majority groups. For example, in 1867, women's right to vote in the United States (US) was first put to

popular (male) vote in the form of the Kansas Suffrage Referendum. It was defeated. A century later, in the case of Loving v. Virginia (1967), the US Supreme Court ruled that laws prohibiting marriage between men and women of different races were unconstitutional. Although the methods and results of these important civil rights decisions varied, the decisions themselves were accompanied by extensive social debate, which called into question the social value of target minority groups (i.e., women, interracial couples), often in disparaging ways. Despite this, the focus of psychological research into the ways that policy change effects the lives of minority group members has been on the impact of changes in the policies themselves (e.g., Hatzenbuehler, 2014). However, the potentially negative psychological impact of the devaluing social discourse in which these important decisions are taking place has yet to receive sufficient empirical attention.

Perhaps the most prominent contemporary example of such a policy decision and accompanying debates has concerned the legal status of same-sex relationships. In the new millennium, rights for same-sex couples in the US became a focal political and social issue, with policies being enacted in state after state to either restrict same-sex couples from marrying or to grant them the right. With the legal status of same-sex marriage in limbo, sexual minority individuals often found themselves and their relationships the topic of heated discussions within their communities. Such discourse, often devaluing, likely has negative impacts on the 
psychological and relational well-being of sexual minority individuals and same-sex couples. Although the Supreme Court's decision in Hollingsworth v. Perry allowed same-sex couples in the US to marry, debates regarding the right to marry continue, and same-sex couples are still a target of a potentially damaging social discourse. Debates also continue internationally (e.g., Northern Ireland, Australia), where most countries do not provide access to marriage for samesex couples and where communities are in protracted debates about the status of sexual minority individuals and their relationships. Building on the minority stress framework (Meyer, 2003, Frost \& Meyer, 2013), the current research examined individual and relational consequences of exposure to negative campaign messages surrounding marriage equality campaigns.

\section{The Role of Minority Stress in the Well-Being of Sexual Minorities}

Existing epidemiological research concludes that sexual minorities have higher rates of mental and physical health problems than their heterosexual peers (for reviews and meta-analysis see Institute of Medicine, 2011; King et al., 2008; Lick, Durso, \& Johnson, 2013). These health disparities are not likely to be caused by or inherent to sexual minority identities in and of themselves. Instead, theory and research suggest that these health disparities are attributable to the fact that sexual minority individuals are exposed to more social stress than their heterosexual peers because of their stigmatized social status (DiPlacido, 1998; Hatzenbuehler et al., 2014;

Herek \& Garnets, 2007; Meyer, Schwartz, \& Frost, 2008). Thus, excess exposure to social stress puts sexual minority individuals at heightened risk for negative health outcomes.

Meyer (1995; 2003) refers to these stigma-related social stressors as minority stressors. In the minority stress theoretical framework, factors such as expectations of rejection, concealment of a stigmatized identity, internalization of negative social beliefs about one's social groups or social identity, and experiences of discrimination (both acute events and chronic 
everyday mistreatment) constitute stressors. These factors stem from and reaffirm a hostile every-day environment for sexual minority men and women characterized by frequent exposure to minority stress.

The minority stress framework organizes these stigma-related social stressors on a continuum of proximity to the self (Meyer, 2003). Stressors most distal to the self are objective stressors based primarily in the environment, such as discriminatory laws and policies, prevailing stereotypes, prejudice, and interpersonal discrimination. These lead to more proximal appraisals of the environment as threatening and resulting expectations of rejection. Most proximal to the self are one's internalizations of negative social attitudes towards one's minority group (e.g., internalized homophobia). Minority stressors have been hypothesized to create strain on individuals' ability to adapt to and function in their everyday environments and are therefore associated with decreases in mental health and well-being (Fingerhut, Peplau, \& Gable, 2010; Kuyper \& Fokkema, 2011; Lehavot \& Simoni, 2011; Mays \& Cochran, 2001; Meyer, 1995). More recent research has identified non-event stressors-or stress that results from denial of opportunities and hoped for accomplishments that do not come to pass - as an additional source of minority stress given sexual minority individuals are more often blocked from achieving their life goals that heterosexuals because of their stigmatized status (Frost \& LeBlanc, 2014; Frost, 2011; Meyer \& Dean, 1998; Meyer, Ouellette, Haile, \& McFarlane, 2011; Pearlin, 1999).

Sexual minority individuals in same-sex relationships are potentially exposed to additional and unique forms of minority stress because they are not only stigmatized as individuals, but the status of their relationship is also disadvantaged relative to heterosexual relationships (LeBlanc, Frost, \& Wight, 2015). At the structural and most distal level (i.e., laws and policies), same-sex couples are denied access to the same forms of legal relationship 
recognition that are afforded to heterosexual couples (i.e., marriage and its corresponding benefits) in the overwhelming majority of countries around the world. Thus the act of denying same-sex couples the right to marry and their accompanying exclusion from the rights of other (heterosexual) citizens, likely diminishes same-sex couples well-being (GLMA, 2008; Herdt \& Kertzner, 2006; Michael King \& Bartlett, 2006). Indeed, this structural stigmatization has been shown to have a negative impact on the health of sexual minority individuals in numerous studies (see Hatzenbuehler, 2014 for a review). To illustrate, Hatzenbuehler and colleagues (2010) analyzed the mental health impact of state-level passage of same-sex marriage bans during the 2004 and 2005 elections. They found that psychiatric disorders increased among sexual minorities (and not heterosexuals) living in states that passed same-sex marriage bans. Disorders among sexual minorities did not increase after the elections in states that did not pass marriage bans.

\section{Expanding the Minority Stress Universe}

The minority stress framework (Meyer, 2003) and recent conceptualizations of structural stigma (Hatzenbuehler et al., 2014) highlight the ways in which discriminatory social policiessuch as bans on same-sex marriage-constitute social stress and can therefore negatively impact the well-being of sexual minority individuals. However, these conceptual frameworks do not adequately account for the degree to which exposure to a devaluing social discourse leading up to the passage or repeal of discriminatory policy may constitute minority stress and have an additional negative impact on sexual minority individuals' and same-sex couples' well-being. In other words, the attention of theory and research efforts has been on documenting the negative effect of discriminatory social policy after its passage. However, not only are same-sex couples barred from marrying in most countries throughout the world, they are reminded of this fact on a 
daily basis by debates among family and coworkers as well as in social and news media in countries and regions where the legality of same-sex marriage is contested (Herek, 2011). During the months leading up to a popular vote on same-sex marriage or pending judicial decision, same-sex couples encounter billboards, yard signs, and bumper stickers against equal access to marriage rights. They also are part of or witness to debates with family, friends, and coworkers about the rights of same-sex couples. These debates extend to popular news media, talk shows, and social media (e.g., Facebook).

While scholars have pointed out the ways in which stigma-related stress may stem from exposure to this devaluing social discourse (e.g., Herek, 2011; Riggle, Thomas, \& Rostosky, 2005; Russell, 2000; Russell \& Richards, 2003) exposure to anti-same sex marriage discourse may represent a unique form of minority stress not yet accounted for in existing theoretical frameworks. Exposure to anti-same sex marriage discourse cannot be accurately described as structural stigma, because it is not always rooted in policy or differential access to participation in society. Indeed, exposure to anti-same sex marriage discourse may occur in contexts in which a marriage ban is under consideration but does not ultimately come to fruition in the form of discriminatory social policy. Furthermore, it does not fall neatly into the minority stress categories of event-based or chronic everyday discrimination because exposure to anti-same sex marriage discourse does not often involve direct disparagement or differential treatment by other people, but rather being party to or encountering overall condemnation for sexual minority individuals or same-sex couples in general, rather than oneself or one's own relationship. Exposure to anti-same sex marriage discourse also does not constitute an expectation of rejection as conceived within the minority stress framework (Meyer, 2003), because it does not manifest in a sexual minority person's fear that he or she will be discriminated against entering into a 
particular social situation. Thus, we contend exposure to anti-same sex marriage discourse constitutes a form of minority stress that occupies a place at the intersection of policy-based discrimination accounted for by frameworks of structural stigma (Hatzenbuehler, 2014) and distal forms of minority stress articulated within the minority stress framework (Meyer, 2003).

Although it has not received adequate attention in these existing theoretical frameworks, some existing evidence suggests exposure to anti-same sex marriage discourse may indeed be experienced by sexual minority individuals as stressful and pose a threat to their well-being. When compared to individuals living in US states with no marriage-related ballot initiatives, individuals in states that passed amendments banning same-sex marriages reported significantly more exposure to stigma related to the negative public discourse around same-sex marriages, as well as significantly more psychological distress (Rostosky, Riggle, Horne, \& Miller, 2009). Because these devaluing social discourses call into question the general value of intimacy and relationships in same-sex couples' lives, their negative impact is likely to be felt regardless of couples' desires to be legally married or publically committed to one another.

\section{The Relational Impact of Exposure to Anti-Same Sex Marriage Discourse}

Although previous research sheds some preliminary light on the psychological consequences of marriage amendments and the debates surrounding these amendments, more research is needed to understand its effects on both individual and relational well-being. The overwhelming majority of studies has focused solely on individual level outcomes and has yet to assess the effects of the same-sex marriage debates on same-sex couples and the quality of their relationships. It is ironic and unfortunate that we know very little about how debates about rights for same-sex couples actually affect couples. In one of the only studies to examine relationship outcomes in the context of same-sex marriage debates, Maisel and Fingerhut (2011) examined 
the effects that the Proposition 8 campaign — a voter initiative to approve a California same-sex marriage ban—had on their relationships with their partners. Participants reported both positive and negative effects. On one hand, the stress of the campaign made them irritable and short tempered with partners; and on the other hand, the visibility of the marriage question often made them appreciate their relationships even more. Thus, the complex effects of exposure to samesex marriage campaigns on same-sex couples' psychological and relational well-being are deserving of additional empirical attention.

\section{Not All Stressors are Created Equal}

Even though same-sex couples experience unique social stressors as a result of their stigmatized social statuses, they also experience the same kinds of day-to-day stressors and hassles that all individuals and couples do, regardless of sexual orientation (LeBlanc et al., 2015). Research on daily hassles in the context of romantic relationships has shown that exposure to chronic stressors (e.g., hassles related to finances, work, home maintenance, parenting, and caretaking) is associated with decreased relationship quality, health, and psychological well-being (e.g., DeLongis, Folkman, \& Lazarus, 1988; Harper, Schaalje, \& Sandberg, 2000). Even further, research on the dyadic nature of stress has shown that one partner's experience of stress can have a negative impact on not only his or her own well-being, but the well-being of his or her partner as well (e.g., Bolger, Delongis, Kessler, \& Wethington, 1989).

Minority stress is theorized to have an effect on well-being above and beyond the effect of general stress common to all couples (LeBlanc et al., 2015). This is potentially due to the fact that minority stress is more salient and disruptive because of its relevance to individuals' identities and relationships. Although this premise has not been examined in the lives of same- 
sex couples, recent research has shown that minority stress in the form of stressful life events stemming from discrimination exerts a greater negative impact on health than general stressful life events (Frost, Lehavot, \& Meyer, 2015). As a result, minority stress resulting from exposure to the negative social discourse surrounding same-sex marriage may exert a negative impact on well-being in couples above and beyond the negative impact of general chronic strain and daily hassles.

\section{The Current Study}

The current study focused on the experience of same-sex couples living in four US states with same-sex marriage amendments on their ballots in the 2012 election. To date, no research on the effects of marriage amendments has collected data from both partners in a couple. The present research directly examined mood and relationship satisfaction in same-sex couples in order to better understand not only individual effects but also dyadic effects of exposure to samesex marriage campaigns on psychological and relational well-being. Previous studies on the psychological consequences of marriage amendments have been retrospective in nature (e.g., participants were queried about their reactions to the campaigns and the associated debates after the election had occurred). The present study aimed to address this issue in two ways. First, we studied same-sex couples' experiences of marriage campaigns in anticipation of the election itself. In this way, we assessed their reactions to the debates and not their reactions to the result of the election. Second, we employed intensive longitudinal daily diary methods to assess couples' daily lived experiences in situ.

We hypothesized that daily exposure to negative same-sex marriage campaign messages would result in diminished psychological well-being (i.e., increases in negative affect, decreases in positive affect) and decreased relational well-being (i.e., decreased relationship satisfaction). 
Furthermore, given the dyadic nature of stress mentioned above, we hypothesized that a given partner's exposure to negative campaign messages would result in negative effects on his or her own psychological and relational well-being (actor effects) as well as his or her partner's psychological and relational well-being (partner effects). In order to examine if exposure to negative campaign messages as minority stress has a greater negative impact than everyday stress on relational and psychological well-being, we tested the hypothesis that daily exposure to negative same-sex marriage campaign messages would persist above and beyond the known negative impact of daily hassles experienced by individuals and their relationship partners.

\section{Method}

\section{Participants}

Participants were recruited from each of the four states (Maine, Maryland, Minnesota, and Washington) where marriage for same-sex couples was subject to a voter referendum. Postings were made in a variety of Internet venues advertising the study (e.g., Facebook groups and volunteer forums within cities within the four states). Additionally, individuals involved in the campaigns in each state who would have contact with LGB individuals were asked to advertise the study and to post recruitment messages to listservs and websites to which they had access. Recruitment messages contained a link to a brief eligibility questionnaire for individuals to find out if they were eligible to participate.

To be eligible to participate, individuals had to be 18 years of age or older, identify as lesbian, gay or bisexual, and live in one of the four states mentioned above. Additionally, participants were required to be in a same-sex relationship and both partners in the couple had to agree to participate. Prior to participation, individuals were screened to make sure that they met eligibility requirements. Participation occurred in three phases, with all phases taking place 
online. First, participants completed an intake survey to obtain demographic information, relationship characteristics, and baseline levels of psychological well-being and relationship satisfaction. In phase 2, participants completed 10 consecutive daily "diary" surveys some time in the month leading up to the election; the diaries assessed daily well-being, relationship satisfaction, as well as exposure to campaign messages related to same-sex marriage and daily hassles. Phase 3 was a follow-up to the intake survey, which occurred in the days immediately following the election. The present analyses only report on data from the first two phases of the study.

A total of 265 individuals completed the eligibility questionnaire and provided an email address and permission to contact their partner. A total of 140 partners completed the eligibility questionnaire. Of those couples in which both partners completed the eligibility questionnaire, 114 couples were determined eligible and invited to complete the intake survey; both partners in 95 couples actually completed the intake survey and were therefore invited to the complete the daily diary phase. In our screening process, we chose to be incredibly conservative as participation occurred online across states, and we therefore had no actual contact with the participants. Given our conservative approach, we excluded an additional 31 couples from the present analysis for a variety of reasons: they withdrew before completing the study, they completed no diaries; in the intake they listed an invalid state, zip code, or listed a different state than their partner or than what they had listed in their original screener; their responses were potentially fraudulent based on multiple IP addresses shared across multiple couples or use of suspicious email addresses (e.g., Partner 1 email = John@gmail.com and Partner 2 email = John@hotmail.com).

The final sample consisted of 64 couples $(N=128)$ who completed the intake survey and 
daily diary components of the study, with the latter yielding a total of 1066 responses. Couples lived across 62 distinct US zip codes within the four states with a same-sex marriage referendum in the 2012 presidential election: Minnesota $(n=29)$; Washington $(n=16)$; Maryland $(n=11)$; and Maine $(n=8)$. On average, couples reported being together for $M=6.8$ years $(S D=4.2)$. Most couples $(n=51)$ were living together, and a minority had obtained legal marriage in another US state $(n=16)$. The majority of the couples were female $(n=50)$ and the majority of participants were White $(n=108)$ and identified as either gay or lesbian $(n=122)$. On average, participants were 33.77 years old $(S D=8.28)$.

\section{Instruments}

Data for the present analyses were drawn from the intake survey and the daily diary forms, which contained the following measures (data source within the study design noted in parentheses).

Exposure to negative campaign messages (daily diary). A measure of exposure to the devaluing social discourse surrounding same-sex marriage referendums was developed for the purposes of this study, given no prior research has examined this form of minority stress in the lives of same-sex couples. Each day, participants were asked to indicate ("yes" or "no") whether or not they were exposed to a variety of messages. The instructions read: "We are interested in hearing about the kinds of exposure you had today to discussions regarding the marriage initiative in your state. Please use the table below to let us know about your experiences IN THE PAST 24 HOURS.” The nine types of messages were: Read newspaper or magazine article(s), either online or in print, about same-sex marriage initiatives; Saw television report(s) about same-sex marriage initiatives; Saw talk show(s) discussion about same-sex marriage initiatives; Saw television commercial(s) about same-sex marriage initiatives; Listened to radio program(s) 
about same-sex marriage initiatives; Saw posting(s) on a social networking site (e.g., Facebook) about same-sex marriage initiatives; Overheard conversation(s) about same-sex marriage initiatives; Participated in conversation(s) about same-sex marriage initiatives; Saw signage regarding same-sex marriage initiatives. If participants said "yes" to experiencing any of the nine items, they were then asked: "Approximately how many did you encounter? [For example, how many signs did you see? Or how many newspaper or magazine articles did you read?]." Further, for each type of message, they were asked to indicate how many of the total number of exposures were "opposed to same-sex marriage" (i.e., negative messages) as well as the number "in favor of same-sex marriage" (i.e., positive messages). For each participant on each day, one number was computed reflecting the total exposure in the past 24 hours to negative and positive campaign messages by summing the total number of messages opposed to and in favor of samesex marriage across the 9 potential exposure types.

Daily hassles (daily diary). As an indicator of general life stressors that could be experienced by any individual or couple — regardless of sexual orientation — we included a measure of daily hassles in the form of five types of commonly experienced chronic stressors or strains. These items reflected five of the seven dimensions of daily hassles identified by Holm and Holroyd (1992): financial concerns ("I had money problems"); time pressure ("I took on too many things at once"); work hassles ("I had a negative experience related to the work I did for school or my job”); health concern (“I experienced illness/physical discomfort”); and family concern ["I had to provide care for another person (e.g., child, parent, significant other )"]. The other two dimensions of inner concern and environmental concern had conceptual overlap with our outcomes (i.e., psychological well-being) and primary predictors (i.e., exposure to negative campaign messages) so we did not include items to reflect these dimensions of daily hassles. 
Participants indicated whether or not they experienced each of the five types of daily hassles each day during the diary-reporting period.

Negative and positive affect (daily diary). Given the necessary brevity of a daily survey, only a handful of items assessing positive and negative affect could be used. Thus, two items from each of the subscales (depression, tension, anger, fatigue, and vigor) of the shortened version of the Profile of Moods States (POMS; Shacham, 1983) were chosen. Negative affect was assessed with the following items: angry, annoyed, anxious, discouraged, tense, unhappy, weary, and worn-out. Positive affect was assessed with two items from the POMS scale: energetic and cheerful. Previous research has suggested that another positive emotion that can result from engagement with gay rights campaigns is pride (Maisel \& Fingerhut, 2011); therefore, we also included "proud" as an item in the positive affect scale. Using a scale ranging from 1 (Not at All) to 5 (Extremely), participants indicated the extent to which they were currently experiencing each of the 11 emotions. Internal consistency reliability for scores on the items in the negative and positive affect scales on the first day of diary reporting were .85 and .78 , respectively.

Relationship satisfaction (intake and daily diary). The four-item version of the Couples Satisfaction Index (CSI; Funk \& Rogge, 2007) was included to assess individuals’ satisfaction with their current primary romantic relationships. The CSI was developed using item response theory and is the result of a factor analysis of items pooled from eight previously validated measures of relationship satisfaction. Example items include: "How rewarding is your relationship with your partner?" and "In general, how satisfied are you with your relationship?" Participants responded to such items on a scale ranging from "not at all" to "completely." The CSI not only demonstrates strong validity correlations with existing measures of the construct, 
but it also demonstrates less noise and more power in detecting individual differences in satisfaction than existing measures (Funk \& Rogge, 2007). The measure is scored on a scale of 0 to 21 , with scores of 13.5 or below indicating relationship distress. In its originating study (Funk \& Rogge, 2007), CSI (four-item) scale scores were internally consistent at .94 and were highly correlated with the eight previously validated measures of relationship satisfaction (rs ranged from .84 to .94). Internal consistency for scores on the CSI measured on the intake survey was .86.

Depressive symptoms (intake). Symptoms of depression were assessed using the short form Center for Epidemiological Studies - Depression scale (CESD; Andresen, Malmgren, Carter, \& Patrick, 1994). The CESD short form is a 10-item measure of depressive symptoms experienced over a one week period prior to the interview. The 10-item version uses a subset of the items from the original 20-item version (Radloff, 1977b). For example, participants were asked how often during the past week they "could not get going," "felt depressed," "felt hopeful about the future," and "felt people dislike you." Participants responded on a 4-point scale ranging from 1 "rarely or none of the time ( $<1$ day)" to 4 "most or all of the time (5-7 days)." The mean response was computed across the 10 items to reflect the average level of depressive symptom frequency experienced in the past week. Numerous studies have demonstrated the convergent validity of the CESD among both clinical and non-clinical samples in the form of large correlations with clinical reports of depression, DSM depression diagnoses, the Hamilton Rating Scale for Depression, and the Symptom Checklist-90 (for a review of validity evidence see McDowell \& Newell, 1996; Roberts, 1983). Although the scale has been shown to correlate moderately to highly with other measures of anxiety and psychological distress, it has been successful in identifying depression in several clinical and community samples (McDowell \& 
Newell, 1996) and as a result is one of the most widely used measures of depressive symptoms. Internal consistency for scores on the CESD measured on the intake survey was .74.

\section{Analysis Strategy}

In order to account for the level of non-independence in the data due to the dyadic and longitudinal nature of the study, we conducted all hypothesis tests using the Actor-Partner Interdependence Model (APIM) within Multilevel Linear Modeling (MLM) procedures using SAS®. Study couples were considered indistinguishable dyads for the purpose of analysis, because members of same-sex couples cannot be distinguished by a common dimension of difference, unlike the way that gender can be used to consistently distinguish between partners across dyads in different-sex couples (Kenny, Kashy, \& Cook., 2006). We followed the approach to longitudinal dyadic data analysis with indistinguishable dyads using SAS PROC MIXED recommended by Kashy and her colleagues (Campbell \& Kashy, 2002; Kashy, Donnellan, Burt, \& McGue, 2008) and implemented in a study of stress and relational well-being in same-sex couples by Totenhagen, Butler, and Ridley (2012). The data contained a three-level nested structure. Level 3 variables were shared characteristics of the couple that were not timevariant (e.g., state of residence, gender, relationship length). Level 2 variables were specific to each partner and were not time-variant (e.g., baseline depressive symptoms, age). Level 1 variables were specific to each partner and time-variant (e.g., daily exposure to negative campaign messages, negative mood). To facilitate interpretation of the resulting model coefficients, all level 2 variables were grand-mean-centered and all level 1 variables were person-mean-centered (Bolger \& Laurenceau, 2013). As specified by Kashy and her colleagues (2008), random intercepts were estimated for each partner and set to be equal. Additionally, compound symmetry was specified for the residual error structure, such that variances of the 
residuals within each day for both partners were set equal and the covariances between partners' residuals across the days were also set to be equal.

In order to test our primary hypotheses, we examined the degree to which daily changes in the primary predictor variable of exposure to negative campaign messages were associated with concomitant changes in three outcome variables: negative mood, positive mood, and relationship satisfaction. Negative and positive mood were considered indicators of psychological well-being, and relationship satisfaction was considered an indicator of relational well-being. We included daily hassles as an additional predictor in all models in order to examine whether the hypothesized impact of exposure to negative campaign messages on psychological and relational well-being indicators was unique and persisted above and beyond the known negative impact of general life stress. Covariates from the baseline survey were also included such that any daily changes observed in psychological and relational well-being controlled for pre-existing individual differences in psychological and relational well-being and could therefore be attributable to changes in our hypothesized predictor variables. Baseline depressive symptoms were included as a covariate in models predicting psychological wellbeing, and baseline relationship satisfaction was included as a covariate for relationship satisfaction. Other level 2 (e.g., age) and level 3 (e.g., state, gender, relationship length) variables were not included in the analyses given (a) they were not central to the testing of our stated hypotheses, and (b) we had to be judicious in including higher level variables in order to maximize statistical power.

In order to examine the dyadic effects inherent to the relational experience of minority stress, we examined both actor and partner effects using the APIM (Kenny et al., 2006). Actor effects refer to the association between one individual's predictor variable and his or her 
outcome (e.g., Partner A's daily exposure to negative campaign messages $\rightarrow$ Partner A's daily report of negative mood). Partner effects refer to the association between one individual's predictor variable and his or her partner's outcome (e.g., Partner A's daily exposure to negative campaign messages $\rightarrow$ Partner B's daily report of negative mood). Actor and partner effects for all predictor variables and covariates were included as fixed effects in tests of the study hypotheses. In order to estimate the APIM in MLM, the data were restructured in pairwise format, as specified by Ledermann and Kenny (2015). Although we did not hypothesize linear change over the 10-day period in any of the psychological and relational well-being outcomes, we included time as a variable in all models in order to account for its potential influence on the outcomes under investigation.

\section{Results}

\section{Descriptive Analyses}

At intake, participants reported generally moderate levels of relationship satisfaction $(M$ $=15.53, S D=3.96)$ and depressive symptoms $(M=1.68, S D=.43)$. At the daily diary level (not taking into account the nested nature of the data), daily reports of negative affect were low $(M=$ $1.77, S D=.64)$ while daily reports of positive affect were in the moderate range $(M=2.62, S D=$ .92). The average number of exposures to negative campaign messages was $M=2.74, S D=$ 7.41. The most frequently experienced forms of exposure to negative campaign messages came in the form of signs $(M=5.49 ; S D=10.49)$ and social media postings $(M=2.11, S D=4.80)$. The least frequently experienced forms of exposure to negative campaign messages came in the form of talk shows $(M=.49 ; S D=.62)$ and radio broadcasts $(M=.63, S D=.72)$.

\section{Tests for the Effect of Time on Study Outcomes}

Prior to testing the study hypotheses using APIM in MLM, we first examined whether 
there was an effect of time on the three outcomes measured in the daily diary component of the study (i.e., negative affect, positive affect, and relationship satisfaction). Although we did not have specific hypotheses that the passage of time would have an effect on the study outcomes or that the effect of predictor variables on the outcomes would vary by time, we tested for the effect of time such that if it was observed, we could control for the change in outcome due to time in tests of study hypotheses. Indeed, we did observe an association between time and negative affect, such that there was a general linear decline in negative affect over the course of the 10 days participants were enrolled in the study (estimate $=-.019, S E=.006, p=.001$ ). A similar linear trend was observed with regard to the effect of time on relationship satisfaction, but in the positive direction (estimate $=.016, S E=.007, p=.02$ ). There was no effect of time on positive affect; however, given its association with 2 out of 3 outcomes, we included a parameter for time in all tests of the study hypotheses using APIM MLM in order to control for its effect on all outcomes in the study.

\section{Tests of Study Hypotheses Using APIM in MLM}

As can be seen in Table 1, we observed a statistically significant positive actor effect of daily exposure to negative campaign messages on negative affect. Specifically, on days in which individuals were exposed to more than their typical amount of negative campaign messages about same-sex marriage, they experienced significant increases in negative affect. There was no effect of daily exposure to negative campaign messages on one's partner's negative affect (i.e., the partner effect was not statistically significant). The effect of exposure to negative campaign messages persisted above and beyond the effects of daily hassles and baseline depression, which were robust as evidenced in statistically significant actor effects (Table 1). There were no partner effects of daily hassles or baseline depression on daily negative affect. 
A similar pattern of associations was observed for positive affect (see Table 2). Namely, we observed a statistically significant actor effect of daily exposure to negative campaign messages on positive affect. Specifically, on days in which individuals were exposed to more than their typical amount of negative campaign messages about same-sex marriage, they experienced significant decreases in positive affect. There was no partner effect of exposure to negative campaign messages on positive affect. The actor effect of exposure to negative campaign messages remained statistically significant controlling for the effects of daily hassles and baseline depressive symptoms. Specifically, one's own experience of daily hassles and one's partner's depression in the week before entering the study were associated with daily levels of positive affect.

Finally, an actor effect of exposure to negative campaign messages was also observed with regard to daily relationship satisfaction (see Table 3). Specifically, on days in which individuals were exposed to more than their typical amount of negative campaign messages about same-sex marriage, they experienced significant decreases in relationship satisfaction. There was no partner effect of daily exposure to negative campaign messages on daily reports of relationship satisfaction. There were significant actor and partner effects for both daily hassles and baseline levels of relationship satisfaction. Given these effects were modeled on the outcome, the marginally significant actor effect of exposure to negative campaign messages on relationship satisfaction is worthy of discussion as it represents an effect above and beyond the actor and partner effects of daily hassles and baseline relationship satisfaction.

In order to confirm that the effects of exposure to negative campaign messages were due to the negative and devaluing valence of the messages rather than exposure to the campaign in and of itself, we repeated all analyses using exposure to positive (i.e., supportive of same-sex 
marriage) campaign messages as the focal exposure variable. No appreciable actor or partner effects emerged in these supplemental analyses for the outcomes of negative affect (Actor $b=$ $.002, S E=.002, t=1.62, p=.11 ;$ Partner $b=.003, S E=.002, t=1.77, p=.08)$ or relationship satisfaction (Actor $b=-.001, S E=.002, t=-0.83, p=.41$; Partner $b=.001, S E=.002, t=0.52, p$ $=.60)$. However, the actor effect in the model predicting positive affect was significant, indicating that on days when individuals were exposed to more than their typical amount of positive campaign messages, they experienced concomitant increases in positive affect $(b=.007$, $S E=.002, t=3.52, p<.001)$. There was no appreciable partner effect of exposure to positive campaign messages on positive affect $(b=-.001, S E=.002, t=-0.71, p=.479)$.

\section{Discussion}

The social discourse that emerges surrounding pending policy decisions about same-sex marriage can have a damaging effect on the psychological and relational well-being of sexual minority individuals and same-sex couples. The present study demonstrates this clearly in the form of consistent evidence that increases in daily exposure to messages against extending marriage rights to same-sex couples result in concomitant increases in negative affect and decreases in positive affect and relational well-being in the days leading up to state-wide ballot initiatives on same-sex marriage. These findings provide a useful complement to studies on structural stigma (e.g., Hatzenbuehler et al., 2010; Rostosky et al., 2009) that have highlighted the negative health consequences of anti-same-sex marriage policies for sexual minority individuals. Namely, the present study shows that regardless of the policy decision itself, the societal conversation that emerges leading up to important policy decisions about same-sex marriage can manifest as a devaluing social discourse surrounding the lives of same-sex couples, and exposure to this devaluing social discourse can have serious and deleterious consequences 
for same-sex couples' psychological and relational well-being. It is important to note that although the effect sizes corresponding to negative campaign exposure were small in size, they are of practical significance given they persisted consistently across multiple outcomes and were controlled for factors known to exert a large influence on well-being, such as daily hassles, baseline depression, and prior reports of relationship satisfaction.

The findings from the present research also have important implications for theory and research on minority stress (e.g., Meyer, 2003; Meyer \& Frost, 2013). Exposure to the devaluing social discourse surrounding decisions on marriage rights represents a unique form of minority stress that is not well articulated within the existing minority stress framework. Importantly, the present study shows that exposure to a devaluing social discourse in the form of anti-same-sex marriage campaign messages is indeed a form of minority stress that exerts a unique impact on same-sex couples' psychological and relational well-being. Our findings show that the negative effects of exposure to anti-same-sex marriage campaign messages persisted above and beyond other forms of stress, measured in the form of daily hassles (Holm \& Holroyd, 1992), which also negatively affected couples' psychological and relational well-being. This is important to note because this pattern of findings indicates that the stress stemming from exposure to the devaluing social discourse that emerges leading up to same-sex marriage policy decisions is a unique form of social stress, adding to the already elevated stress burden of sexual minority populations relative to heterosexuals (Meyer, Schwartz, \& Frost, 2008). Same-sex couples experience the same kinds of stressors that all couples can experience (e.g., money problems, work strain), regardless of sexual orientation; in addition, though, same-sex couples must contend with stressors stemming from their stigmatized social statuses as both sexual minority individuals and members of a same-sex couple. This elevated stress burden accounts for the persistent health 
disparities observed between sexual minority and heterosexual populations (e.g., Mays \& Cochran, 2001; Meyer, 2003).

The present study therefore adds to a small but growing body of work demonstrating how this stress burden extends to the relational domain by demonstrating how minority stress stemming from the stigmatized status associated with being in a same-sex relationship manifests at the couple-level and can negatively affect individual as well as relational indicators of wellbeing (Frost \& LeBlanc, 2014; LeBlanc et al., 2015; Maisel \& Fingerhut, 2011). It should be noted that, although we found an actor effect but not a partner effect of exposure to negative campaign messages, including both actor and partner effects in the models was a strength of the study. This is because our dyadic longitudinal models accounted for the minority stress experiences of same-sex couples as well as sexual minority individuals, taking seriously the relational context as a unit of analysis. Further, the pattern of findings indicated an "actor only" dyadic model with regard to the effects of exposure to negative campaign messages, but the models did demonstrate both actor and partner effects in other instances (e.g., with regard to the impact of daily hassles on relational well-being), and allowed us to control for these influences on psychological and relational well-being in tests of the focal actor effects of primary interest in this study.

It is unclear why the negative effects of exposure to negative campaign messages were limited to actor effects only. Although only speculative, it is possible that partners encountered and experienced negative campaign messages more often on their own than when together, or that they did not discuss such experiences with each other. Thus the experience of the stress associated with exposure to negative campaign messages may be more isolated as an individual experience than stress stemming from daily hassles, for which we did observe a partner effect. 
Although daily exposure to negative campaign messages was uniformly associated with poorer psychological and relational well-being, a linear trend was observed indicating negative affect and relational well-being improved over the course of the reporting period in the present study. Additionally, levels of negative affect were not as high as one might assume would be the case for individuals contending with a hostile environment. Although explaining the cause of this trend is beyond the scope of the present data, it may have been the result of two possible scenarios. First, same-sex marriage rights were achieved as a result of the elections in all four states that were sampled in the present study. Couples may have been aware of polling trends that emerged in line with potential favorable outcomes as the date of the elections drew nearer, causing them to feel more optimistic and valued within their relationships, despite the negative daily impact of exposure to anti-same-sex marriage campaign messages. Second, exposure to anti-same-sex marriage campaign messages may have led participants to seek support from their partners. Evidence from prior research on how same-sex couples experience intimacy in the context of stigmatizing social climates has indicated that some members of same-sex couples are able to frame their initially negative experiences of stigma as a challenge that ultimately brings them closer together and increases their commitment and bond to one another (Frost, 2011, 2014). Although these may be two potential explanations of this trend, they are purely speculative and do not account for the fact that improvement was not observed in positive affect, making this trend inconsistent across study outcomes. However, the fact that we controlled for improvement in negative affect and relational well-being over time only lends further confidence to our conclusions that when couples were exposed to negative campaign messages, exposure was detrimental to their psychological and relational well-being, perhaps despite their anticipation of a positive election result and attempts to cope with the daily stress of negative 
campaign exposure.

\section{Limitations}

The findings from the present study should be considered in light of the following limitations. First, we had a relatively small sample of couples. Although the sample size is small, the number of daily reports and resulting multiple observations improves the ability of the study to determine how the constructs of interest (i.e., exposure to devaluing social discourse) vary from one day to the next and the resulting changes this daily variation may have for the outcomes measured in the study. Another possible limitation of the sample is participation bias. Given some of our participants were recruited through listservs associated with organizations and groups involved in working toward achieving marriage equality, some of the couples in the study may have been particularly attuned to campaign messages in ways that the average couple may not have been. Finally, due to the practical need to make sure daily diary reports are not burdensome to participants, we were not able to assess additional individual level experiences of minority stress, such as direct forms of discrimination, expectations of rejection, concealment, and internalized homophobia at the daily level. Thus, we were not able to make any claims as to whether the previously unexamined forms of minority stress novel to the current study (i.e., exposure to negative campaign messages) exerted an impact on well-being above and beyond the impact that these previously identified forms of minority stress may exert on psychological and relational well-being.

\section{Conclusions}

Despite these limitations, this study is the first prospective examination to document the ways in which minority stress stemming from the devaluing social discourse that precedes policy decisions regarding same-sex marriage can be damaging for same-sex couples' psychological 
and relational well-being. As decisions about the legality of same-sex marriage are currently being contested in several areas throughout the world (e.g., Northern Ireland, Australia), access to marriage for same-sex couples is constantly shifting and increasingly subject to pending popular vote, legislative action, and judicial decisions. These pending decisions may create a devaluing social discourse like those examined in the present study and negatively impact the lives of same-sex couples living in such areas.

Although the present study focused on decisions surrounding same-sex marriage, there are multiple historical moments in which the rights of stigmatized minority group members are subject to decisions made by the voting public or powerful members of the majority. Within democracies, the rights of minority group members will continue to be determined by voter referendums and large-scale legal decisions that produce societal debate. Same-sex marriage is only one of a number of such issues. Present examples include debates over immigrant rights in Europe, voter rights acts and the availability of cultural studies programs in US schools. The social conditions associated with these policy decisions allow for devaluing and potentially toxic social discourses to emerge. Not only are there important implications that result from the policy decisions themselves, the findings from the present study indicate that researchers and clinicians must take action to better understand and document the potential negative psychological impacts of emerging social discourses and strive to protect the health and well-being of minority group members when these historical moments arise. 


\section{References}

Andresen, E. M., Malmgren, J. A., Carter, W. B., \& Patrick, D. L. (1994). Screening for depression in well older adults: Evaluation of a short form of the CES-D. American Journal of Preventive Medicine, 10, 77-84.

Bolger, N., Delongis, Kessler, \& Wethington. (1989). The contagion of stress across multiple roles. Journal of Marriage and the Family, 175-183.

Bolger, N., \& Laurenceau, J.-P. (2013). Intensive longitudinal methods: An introduction to diary and experience sampling research. Guilford Press.

Campbell, L., \& Kashy, D. A. (2002). Estimating Actor, Partner, and Interaction Effects for Dyadic Data Using PROC MIXED and HLM: A User-Friendly Guide. Personal Relationships, 9(3), 327-342.

DeLongis, A., Folkman, S., \& Lazarus, R. S. (1988). The impact of daily stress on health and mood: Psychological and social resources as mediators. Journal of Personality and Social psychology1, 54(3), 486-495.

DiPlacido, J. (1998). Minority stress among lesbians, gay men, and bisexuals: A consequence of heterosexism, homophobia, and stigmatization. In G. M. Herek (Ed.), Stigma and Sexual Orientation (pp. 138-159). Thousand Oaks, CA US: Sage Publications, Inc.

Fingerhut, A. W., Peplau, L. A., \& Gable, S. L. (2010). Identity, minority stress and psychological well-being among gay men and lesbians. Psychology \& Sexuality.

Frost, D. M. (2011). Stigma and intimacy in same-sex relationships: A narrative approach. Journal of Family Psychology, 25(1), 1-10. 
Frost, D. M., \& LeBlanc, A. J. (2014). Nonevent stress contributes to mental health disparities based on sexual orientation: Evidence from a personal projects analysis. American Journal of Orthopsychiatry, 84(5), 557-566.

Frost, D. M., Lehavot, K., \& Meyer, I. H. (2015). Minority stress and physical health among sexual minority individuals. Journal of Behavioral Medicine, 38(1), 1-8.

Funk, J. L., \& Rogge, R. D. (2007). Testing the ruler with item response theory: Increasing precision of measurement for relationship satisfaction with the Couples Satisfaction Index. Journal of Family Psychology, 21(4), 572-583.

Gay and Lesbian Medical Association (GLMA) Marriage Initiative (2008, September). SameSex Marriage and Health.

Harper, J. M., Schaalje, B. G., \& Sandberg, J. G. (2000). Daily Hassles, Intimacy, and Marital Quality in Later Life Marriages. The American Journal of Family Therapy, 28(1), 1-18.

Hatzenbuehler, M. L. (2014). Structural stigma and the health of lesbian, gay, and bisexual populations. Current Directions in Psychological Science, 23(2) 127-132.

Hatzenbuehler, M. L., McLaughlin, K. A., Keyes, K. M., \& Hasin, D. S. (2010). The impact of institutional discrimination on psychiatric disorders in lesbian, gay, and bisexual populations: a prospective study. American Journal of Public Health, 100(3), 452-459.

Herdt, G., \& Kertzner, R. (2006). I do, but I can't: The impact of marriage denial on the mental health and sexual citizenship of lesbians and gay men in the United States. Sexuality Research \& Social Policy: A Journal of the NSRC, 3(1), 33-49.

Herek, G. M. (2011). Anti-Equality Marriage Amendments and Sexual Stigma. Journal of Social Issues, 67(2), 413-426. 
Herek, G. M., \& Garnets, L. D. (2007). Sexual orientation and mental health. Annual Review of Clinical Psychology, 3, 353-375.

Holm, J. E., \& Holroyd, K. A. (1992). The Daily Hassles Scale (Revised): Does it measure stress or symptoms? Behavioral Assessment, 14(3-4), 465-482.

Institute of Medicine (2011). The health of lesbian, gay, bisexual, and transgender people: Building a foundation for better understanding. Washington, DC: The National Academies Press.

Kashy, D. A., Donnellan, M. B., Burt, S. A., \& McGue, M. (2008). Growth curve models for indistinguishable dyads using multilevel modeling and structural equation modeling: The case of adolescent twins' conflict with their mothers. Developmental Psychology, 44(2), $316-329$.

Kenny, D. A., Kashy, D. A., \& Cook., W. L. (2006). Dyadic data analysis. Guilford Press.

King, M., \& Bartlett, A. (2006). What same sex civil partnerships may mean for health. Journal of Epidemiology \& Community Health, 60, 188-191.

King, M., Semlyen, J., See Tai, S., Killaspy, H., Osborn, D., Popelyuk, K., \& Nazareth, I. (2008). A systematic review of mental disorder, suicide, and deliberate self harm in lesbian, gay and bisexual people: a systematic review. BMC Psychiatry, 8, 70.

Kuyper, L., \& Fokkema, T. (2011). Minority stress and mental health among Dutch LGBs: examination of differences between sex and sexual orientation. Journal of Counseling Psychology, 58(2), 222-33.

LeBlanc, A. J., Frost, D. M., \& Wight, R. G. (2015). Minority Stress and Stress Proliferation Among Same-Sex and Other Marginalized Couples. Journal of Marriage and Family, 77(1), 40-59. 
Ledermann, T., \& Kenny, D. A. (2015). A toolbox with programs to restructure and describe dyadic data. Journal of Social and Personal Relationships, 32, 997-1011.

Lehavot, K., \& Simoni, J. M. (2011). The impact of minority stress on mental health and substance use among sexual minority women. Journal of Consulting and Clinical Psychology, 79(2), 159-170.

Lick, D. J., Durso, L. E., \& Johnson, K. L. (2013). Minority Stress and Physical Health Among Sexual Minorities. Perspectives on Psychological Science, 8(5), 521-548.

Maisel, N. C., \& Fingerhut, A. W. (2011). California's Ban on Same-Sex Marriage: The Campaign and its Effects on Gay, Lesbian, and Bisexual Individuals. Journal of Social Issues, 67(2), 242-263.

Mays, V. M., \& Cochran, S. D. (2001). Mental health correlates of perceived discrimination among lesbian, gay, and bisexual adults in the United States. American Journal of Public Health, 91(11), 1869-76.

McDowell, I., \& Newell, C. (1996). Measuring health: A guide to rating scales and questionnaires (2nd ed.). New York, NY US: Oxford University Press.

Meyer, I. H. (1995). Minority stress and mental health in gay men. Journal of Health and Social Behavior, 36(1), 38-56.

Meyer, I. H., \& Dean, L. (1998). Internalized homophobia, intimacy, and sexual behavior among gay and bisexual men. In G. M. Herek (Ed.), Stigma and sexual orientation: Understanding prejudice against lesbians, gay men, and bisexuals (pp. 160-186). Thousand Oaks, CA US: Sage Publications, Inc. 
Meyer, I. H. (2003). Prejudice, social stress, and mental health in lesbian, gay, and bisexual populations: conceptual issues and research evidence. Psychological Bulletin, 129(5), 674697.

Meyer, I. H., Schwartz, S., \& Frost, D. M. (2008). Social patterning of stress and coping: Does disadvantaged social statuses confer more stress and fewer coping resources? Social Science \& Medicine, 67(3), 368-379.

Meyer, I. H., Ouellette, S. C., Haile, R., \& McFarlane, T. A. (2011). “We'd Be Free”: Narratives of Life Without Homophobia, Racism, or Sexism. Sexuality Research \& Social Policy, 8(3), 204-214.

Pearlin, L. I. (1999). The stress process revisited. In C S. Aneshensel \& J. C. Phelan (Eds.) Handbook of the Sociology of Mental Health (pp. 395-415). Springer US.

Radloff, L. S. (1977). The CES-D Scale: A self-report depression scale for research in the general population. Applied Psychological Measurement, 1, 385-401.

Riggle, E. D. B., Thomas, J. D., \& Rostosky, S. S. (2005). The marriage debate and minority stress. PS: Political Science and Politics, 38(2), 221-224.

Roberts, R. E. (1983). The Center for Epidemiological Studies Depression Scale: Its use in a community sample. American Journal of Psychiatry, 140(1), 41-46.

Rostosky, S. S., Riggle, E. D. B., Horne, S. G., \& Miller, A. D. (2009). Marriage amendments and psychological distress in lesbian, gay, and bisexual (LGB) adults. Journal of Counseling Psychology, 56(1), 56-66.

Russell, G. M. (2000). Voted out: The psychological consequences of anti-gay politics. New York, NY: New York Univeristy Press. 
Russell, G. M., \& Richards, J. a. (2003). Stressor and resilience factors for lesbians, gay men, and bisexuals confronting antigay politics. American Journal of Community Psychology, 31(3-4), 313-28.

Shacham, S. (1983). A shortened version of the Profile of Mood States. Journal of Personality Assessment, 47(3), 305-6.

Totenhagen, C. J., Butler, E. A., \& Ridley, C. A. (2012). Daily stress, closeness, and satisfaction in gay and lesbian couples. Personal Relationships, 19(2), 219-233. 
Table 1. Explaining daily negative affect with daily exposure to negative campaign messages and daily hassles.

\begin{tabular}{|c|c|c|c|c|}
\hline Effect & Estimate & $S E$ & $\boldsymbol{t}$ & $p$ \\
\hline Intercept & 1.820 & 0.047 & 38.64 & $<.001$ \\
\hline Time & -0.014 & 0.006 & -2.3 & 0.022 \\
\hline Exposure to Negative Campaign Messages (Actor) & 0.007 & 0.003 & 2.63 & 0.009 \\
\hline Exposure to Negative Campaign Messages (Partner) & 0.001 & 0.003 & 0.44 & 0.662 \\
\hline Daily Hassles (Actor) & 0.159 & 0.021 & 7.6 & $<.001$ \\
\hline Daily Hassles (Partner) & -0.019 & 0.021 & -0.91 & 0.364 \\
\hline Baseline Depressive Symptoms (Actor) & 0.472 & 0.075 & 6.29 & $<.001$ \\
\hline Baseline Depressive Symptoms (Partner) & -0.018 & 0.075 & -0.24 & 0.807 \\
\hline
\end{tabular}


Table 2. Explaining daily positive affect with daily exposure to negative campaign messages and daily hassles.

\begin{tabular}{|c|c|c|c|c|}
\hline Effect & Estimate & $S E$ & $t$ & $p$ \\
\hline Intercept & 2.630 & 0.078 & 33.74 & $<.0001$ \\
\hline Time & -0.011 & 0.008 & -1.51 & 0.132 \\
\hline Exposure to Negative Campaign Messages (Actor) & -0.007 & 0.003 & -2.21 & 0.028 \\
\hline Exposure to Negative Campaign Messages (Partner) & 0.000 & 0.003 & 0.11 & 0.910 \\
\hline Daily Hassles (Actor) & -0.137 & 0.027 & -5.13 & $<.0001$ \\
\hline Daily Hassles (Partner) & 0.014 & 0.027 & 0.51 & 0.610 \\
\hline Baseline Depressive Symptoms (Actor) & -0.227 & 0.133 & -1.70 & 0.091 \\
\hline Baseline Depressive Symptoms (Partner) & -0.546 & 0.133 & -4.10 & $<.0001$ \\
\hline
\end{tabular}


Table 3. Explaining daily relationship satisfaction with daily exposure to negative campaign messages and daily hassles.

\begin{tabular}{|c|c|c|c|c|}
\hline Effect & Estimate & $S E$ & $t$ & $p$ \\
\hline Intercept & -0.095 & 0.059 & -1.62 & 0.109 \\
\hline Time & 0.008 & 0.007 & 1.14 & 0.254 \\
\hline Exposure to Negative Campaign Messages (Actor) & -0.006 & 0.003 & -1.95 & 0.051 \\
\hline Exposure to Negative Campaign Messages (Partner) & -0.002 & 0.003 & -0.85 & 0.394 \\
\hline Daily Hassles (Actor) & -0.099 & 0.023 & -4.28 & $<.001$ \\
\hline Daily Hassles (Partner) & -0.059 & 0.023 & -2.56 & 0.011 \\
\hline Baseline Relationship Satisfaction (Actor) & 0.136 & 0.014 & 9.45 & $<.001$ \\
\hline Baseline Relationship Satisfaction (Partner) & 0.076 & 0.014 & 5.33 & $<.001$ \\
\hline
\end{tabular}

